\title{
Caracterização de $E R 49$, um fator de elongação da síntese de proteínas do tipo Ts, expresso durante a maturação do fruto de tomate
}

\author{
Ana Lúcia S. Chaves ${ }^{1}$, J.A. Silva1, J.-C. Pech², A. Latche², M. Bouzayen², H. Zegzouti² \\ and Cesar V. Rombaldi ${ }^{1}$
}

${ }^{1}$ Departamento de Ciência e Tecnologia Agroindustrial, Faculdade de Agronomia Eliseu Maciel, CP 354, Universidade Federal de Pelotas , 96010-900, Pelotas, RS, Brasil; '2ENSAT-INRA, Laboratoire Biologie Moléculare et Physiologie de la Maturation des Fruits, Avenue de l'Agrobiopole, BP 107, 31326, Auzeville Tolosane, Castanet Tolosan Cedex, France

O etileno, conhecido, sobretudo, como o fitormônio da maturação de frutos, está envolvido em vários processos fisiológicos, atuando na regulação da expressão de grande número de genes. O clone parcial de cDNA ER49 foi previamente isolado mediante a técnica do "Differential Display". A obtenção e a análise da seqüência completa confirmaram as homologias significativas com fatores de elongação da síntese de proteínas do tipo Ts. Tais proteínas são responsáveis pela reciclagem do complexo EF-Tu•GDP, que atua na ligação do aminoacil-RNAt ao ribossomo. A predição da seqüência protéica permitiu a detecção de um peptídio sinal de endereçamento para a mitocôndria e dos domínios TS-N e EF-Ts. A modelagem da estrutura terciária mostrou que ER49 poderia interagir com EF-Tu॰GDP, para promover a reciclagem de GDP em GTP. Estudos de expressão durante a maturação do fruto de tomate (Lycopersicon esculentum Mill.), var. MicroTom, foram realizados por RT-PCR, revelando que ER49 tem sua expressão induzida nos últimos estádios de maturação do fruto. Os resultados da análise do DNA genômico por Southern blot sugerem que ER49 faz parte de uma família multigênica de 2-3 elementos. Através de ER49, gene mitocondrial regulado pelo etileno, surgem novas perspectivas para o estudo da regulação de genes em nível pós-transcricional e de sua relação com o metabolismo respiratório.

Palavras-chave: EF-Ts, etileno, frutos climatéricos, Lycopersicon esculentum, regulação pós-transcricional.

Characterisation of ER49, a Ts type protein synthesis elongation factor, expressed during tomato fruit maturation: The plant hormone ethylene, known as the fruit ripening hormone, plays a role in several physiological processes and is involved in the regulation of gene expression. The partial cDNA clone ER49 was previously isolated by Differential Display screening. Full-length sequence analysis has confirmed significant homologies with TS protein synthesis elongation factors. These proteins are responsible for GDP exchange in the EF-Tu॰GDP complex which is necessary for aminoacylRNAt binding to ribosome. Peptidic sequence prediction allowed the detection of a mitochondrial targeting signal and TS$\mathrm{N}$ and EF-Ts domains. The modeling of tertiary protein structure has shown that ER49 could interact with EF-Tu•GDP and promote GTP exchange. Expression patterns during tomato fruit ripening (Lycopersicon esculentum Mill.), var. MicroTom were obtained by RT-PCR, showing that ER49 is up-regulated in the last stages of fruit ripening. Southern analysis suggested that ER49 is encoded by a multigene family of 2-3 elements. Study of this gene has opened new perspective on the understanding of post transcriptional gene regulation by ethylene and its relationship with the respiratory metabolism.

Key words: climacteric fruits, EF-Ts, ethylene, Lycopersicon esculentum, post-transcriptional regulation, ripening. 


\section{INTRODUÇÃO}

A demonstração de que os tecidos vegetais produzem etileno, um hidrocarboneto insaturado de dois carbonos, data de mais de meio século. A partir daí, vários trabalhos demonstraram a implicação desse regulador de crescimento em numerosas fases do desenvolvimento das plantas, como a germinação de sementes, a senescência e abscisão de folhas e de flores, o crescimento e desenvolvimento de raízes e a senescência de folhas e de flores, bem como a embriogênese somática. O etileno, porém, é conhecido, sobretudo, como o fitormônio da maturação de frutos climatéricos (Pech et al., 1992).

Em frutos climatéricos, tais como o tomate, a maçã, o pêssego, a pêra, o melão, o abacate e o quivi (kiwi), o processo de maturação/senescência é acompanhado de um incremento da síntese de etileno e da intensidade respiratória (crise climatérica) (Chitarra and Chitarra, 1990). Durante a maturação desses frutos, as mudanças bioquímicas que ocorrem conferem-lhes suas qualidades organolépticas, o que se traduz pela modificação de cor, textura e sabor (Seymour et al., 1993).

O fenômeno da crise climatérica é acompanhado por mudanças importantes ao nível de expressão de genes, os quais são induzidos pelo etileno (Slater et al.,1985). De fato, vários cDNAs que correspondem a genes que se acumulam em abundância durante a maturação do tomate ou em resposta ao etileno foram isolados (Lincoln et al., 1987; Maunders et al., 1987) e caracterizados (Hamilton et al., 1990; Picton et al., 1993; Gray et al., 1994).

A diversidade e a amplitude das respostas fisiológicas e bioquímicas dos frutos ao etileno sugerem que este fitormônio controla a expressão de grande número de genes, intervindo, em nível molecular, através de uma cadeia de transdução de sinais (Giovannoni, 2001).

Muitos eventos moleculares implicados no processo de maturação dos frutos foram estudados mediante a utilização de métodos clássicos de screening diferencial de bancos de cDNA de frutos maduros. Isolaram-se vários genes, cuja expressão é regulada pelo etileno ou induzidos durante a maturação, mas os conhecimentos sobre a homologia de seqüência com outros genes já caracterizados, mecanismos de regulação e função específica de grande parte deles ainda são insuficientes (Zegzouti, 1997).

Sabe-se que a regulação da expressão gênica pode sofrer intervenções nos níveis transcricional e pós- transcricional. Até agora, somente os mecanismos da regulação transcricional de genes controlados pelo etileno, foram estudados, por meio da caracterização de elementos cis e trans (Bouquin et al., 1997; Coupe and Deikman,1997, Lasserre et al., 1997), restando, ainda, elucidar os eventos relacionados à intervenção do fitormônio na regulação póstranscricional.

Através da técnica de Differential Display-RT-PCR (DDRT-PCR) (Liang and Pardee, 1992; Zegzouti et al., 1997), identificaram-se 19 novos genes regulados pelo etileno (ER), encontrando-se entre eles, o ER49. A técnica empregada originou clones parciais incompletos, correspondentes essencialmente às extremidades 3 '. No caso do clone ER49, a seqüência isolada continha 199 pb na região codificante. As pesquisas de homologia com genes já conhecidos indicaram que o clone em questão corresponderia, potencialmente, a um fator de elongação (EF) da síntese de proteínas do tipo Ts (Zegzouti et al., 1999).

Em Escherichia coli, o fator de elongação EF-Ts participa da síntese de proteínas associado a outro fator de elongação, EF-Tu, que atua na ligação do aminoacil-RNAt ao complexo RNAm-ribossomo. EF-Tu apresenta-se na forma ativa quando complexado com GTP, que fornece a energia necessária para a ligação do aminoacil-RNAt no sitio A ribossomal, no momento do reconhecimento códonanticódon, ao ser hidrolisado em GDP. Após a hidrólise, o complexo EF-Tu•GDP é liberado do ribossomo. A reciclagem do GDP em GTP é feita graças ao fator EF-Ts, o qual forma um complexo intermediário EF-Tu•GDP•EFTs (Miller and Weissbach, 1977).

Outros fatores de elongação do tipo Ts foram identificados e caracterizados em procariotos. Esses EFs procarióticos apresentam fortes homologias de seqüência com fatores de elongação eucarióticos mitocondriais e cloroplásticos de animais e vegetais. Alguns EFs do tipo Tu e Ts mitocondriais já foram isolados e caracterizados em Bos taurus e em Homo sapiens, assim como no nematóide Caenorhabditis elegans. Em Arabidopsis thaliana, caracterizou-se apenas um EF-Tu mitocondrial e isolou-se um potencial EF-Ts. Identificaram-se, ainda, alguns EF-Ts cloroplásticos em vegetais inferiores, como Porphyra purpurea, Cyanidium caldarium e Euglena gracilis. Esses genes apresentam equivalentes funcionais citoplasmáticos, denominados EF-1 $\alpha$ (equivalente de EF$\mathrm{Tu}$ ) e EF-1 $\beta$ (equivalente de EF-Ts). Em vegetais, nenhum EF-Ts mitocondrial foi isolado, o que faz de ER49 o pri- 
meiro gene do tipo relatado até o momento. Esse grupo de proteínas, por sua implicação na tradução mitocondrial, pode servir a estudos moleculares, bioquímicos e fisiológicos, na busca do estabelecimento de um elo entre etileno e regulação pós-transcricional, e também no entendimento dos processos envolvidos na crise climatérica, ao relacionar etileno e metabolismo respiratório (Chaves, 2001).

O objetivo deste trabalho foi caracterizar o clone ER49, mediante (a) análise da seqüência protéica, predita a partir da seqüência nucleotídica do cDNA após o isolamento da extremidade 5 ' (etapa posterior ao isolamento por Differential Display); (b) verificação da sua expressão durante a maturação do fruto de tomate, por RT-PCR; e (c) determinação do número de cópias presentes no genoma de tomate.

\section{MATERIAL E MÉTODOS}

Obtenção da extremidade 5' do clone isolado por Differential Display: A extremidade 5' do clone ER49 foi obtida por amplificação com PCR, utilizando-se como DNA molde um banco de cDNA de frutos de tomate, clonado no vetor $\lambda$ ZAP pBluescript. Para isso, utilizou-se o oligonucleotídeo específico ER49-3' (5'CAAGCAGCATTAGCCAAAGGTTC3') combinado com o oligonucleotídeo universal KS New (5'CCTCGAGGTCGACGGTATCG3') ou SK+ (5'CGCTCTAGAACTAGTGGATCCC3'). Realizaram-se as amplificações utilizando-se a enzima Taq DNA Polimerase em termociclador Robocycler Gradient 40 (Stratagene), estabelecendo-se as condições de temperatura das reações de acordo com a Tm teórica dos oligonucleotídeos. Após amplificação, clonou-se o fragmento de DNA de tamanho superior ao fragmento inicial no vetor pGEMT-easy (Promega), de acordo com as recomendações do fornecedor. A construção foi utilizada para a transformaçao de $E$. coli DH5 $\alpha$ (Life Technologies). Selecionaram-se as bactérias recombinantes em meio LB sólido, contendo ampicilina a $50 \mu \mathrm{g} . \mu \mathrm{L}^{-1}$, IPTG e X-gal, realizando-se duas PCRs sobre cada colônia, utilizando-se o oligonucleotídeo ER493', combinado com o oligonucleotídeo M13 forward (5'GTTTTCCCAGTCACGACGTTGTA3') ou M13 reverse (5'AATTGTGAGCGGATAACAATTTC3'). Efetuaram-se as reações de PCR conforme citado. A partir das colônias identificadas como portadoras do fragmento de tamanho superior ao inicial, realizaram-se minipreparações de DNA plasmidial utilizando-se colunas Spin column, do kit Wizard
Plus SV Minipreps (Promega), de acordo com as recomendações do fabricante. Os clones foram seqüenciados pelo método de Sanger (Sanger and Coulson, 1975), empregando-se a enzima Thermosequenase (Amersham Pharmacia Biotech), conforme as recomendações do fabricante. As reações foram realizadas em presença de $\left[\alpha-{ }^{33} \mathrm{P}\right] \mathrm{dATP}$, obtendo-se, dessa forma, clones parciais. Repetiu-se o procedimento com a escolha de outros oligonucleotídeos na região 5' da ultima seqüência isolada, para outras amplificações a partir do banco de cDNA de frutos de tomate, até a obtenção de um fragmento que apresentasse uma fase aberta de leitura. Obtida a seqüência correspondente à extremidade 5', novo oligonucleotídeo foi escolhido sobre essa região, denominado

ER49-Full5

(5'CCTCCTGATTAGCATCACAGATC3'), com o objetivo de amplificar, juntamente com o oligonucleotídeo inicial ER49-3', o fragmento correspondente ao clone completo ER49. Os alinhamentos com seqüências conhecidas já publicadas foram realizados através do programa Basic Local Alignement Search Tool - BLAST (Altschul et al., 1997).

Material vegetal: Utilizaram-se plantas de tomateiro (Lycopersicon esculentum Mill.) cv. Micro-Tom como material vegetal. O cultivo foi realizado em salas (fitotrons) sob condições controladas de fotoperíodo $(16 \mathrm{~h} \mathrm{dia} / 8 \mathrm{~h}$ noite), temperatura $\left(25^{\circ} \mathrm{C}\right)$, umidade $(80 \%)$ e intensidade luminosa $\left(250 \mu \mathrm{E} \cdot \mathrm{s}^{-1} \cdot \mathrm{m}^{-2}\right)$. A intensidade luminosa foi obtida pelo uso de lâmpadas fluorescentes do tipo branca fria e growlux na proporção de 5:1, efetuando-se todos os tratos culturais recomendados por Filgueira (1982) para a cultura do tomateiro.

Identificação dos estádios de maturação dos frutos de tomate: Realizou-se tal identificação mediante a comparação com uma escala colorimétrica, baseando-se nos níveis de desenvolvimento de pigmentos no fruto, a qual é amplamente adotada em estudos sobre a maturação do tomate (Hamilton, 1990; Gray et al., 1994; Zegzouti et al., 1999). A correlação entre a coloração observada visualmente (avaliação subjetiva) e os valores de coloração do sistema $\mathrm{L} * \mathrm{a} * \mathrm{~b} *$ (avaliação objetiva) foi possível pelo emprego de um colorímetro Minolta (modelo CR-200). Frutos nos estádios verde-maduro (VM), breaker $(\mathrm{Br})$, turning $(\mathrm{Tu})$, e vermelho (V), foram colhidos e imediatamente congelados em $\mathrm{N}_{2}$ líquido, e armazenados a $-80{ }^{\circ} \mathrm{C}$ até a extração de RNAs. 
RT-PCR: Realizou-se a extração de RNA total dos frutos de tomate nos estádios $\mathrm{VM}, \mathrm{Br}$, Tu e V, de acordo com o protocolo descrito por Boss et al. (1996). Os RNAs extraídos foram tratados com DNase I (Roche). A quantificação dos RNAs totais extraídos foi em $260 \mathrm{~nm}$ e a análise qualitativa, pela verificação da pureza (relação $\mathrm{DO}_{260}\left(\mathrm{DO}_{280}\right.$ ), da integridade e da presença de DNA residual (por separação em gel de agarose). As reações de transcrição reversa foram feitas a partir de $10 \mu \mathrm{g}$ de RNA total, em presença da enzima RT-MMuLV (Stratagene) e de inibidor de RNases RNasin (Promega). PCRs semiquantitativas foram realizadas conforme citado para a obtenção da extremidade 5', sobre $1 \mu \mathrm{L}$ de cDNAs correspondentes aos estádios de maturação $\mathrm{VM}, \mathrm{Br}, \mathrm{Tu}$ e V. Utilizaram-se os oligonucleotídeos

ER 49-RT 5'

(5'CCTCAGAATGCTGTAGAAAAAATG3') e ER49 3', os quais amplificam um fragmento de $241 \mathrm{pb}$. O gene $u b i 3$ (Hoffman et al., 1991) foi utilizado como controle interno da reação. O número de ciclos foi definido de forma a permanecer em condições não saturantes (fase exponencial). Os oligonucleotídeos para amplificação de ubi3, LEubi5' (5'CTAACGGGGAAGACGATCACCC3') e LEubi3' (5'TCCCAAGGGTTGTCACATACATC 3'), os quais amplificam um fragmento de $640 \mathrm{pb}$, foram adicionados 24 ciclos antes do final da reação; já os oligonucleotídeos ER49 estiveram presentes durante os 30 ciclos. Submeteu-se o produto da amplificação à migração em gel de agarose $2 \%$ e, posteriormente, transferido para membrana de náilon (Gene Screen Plus NEN Life Science Technology). Para a hibridação, empregaram-se sondas específicas de ER49 e ubi3, obtidas por PCR, com os oligonucleotídeos específicos (ER49 RT-5'/ ER49-3' e LEubi5'/ LEubi3'), purificadas e marcadas com a enzima fosfatase alcalina pela utilização do sistema Gene Images AlkPhos-Direct (Amersham Life Science). A deteç̧ão foi feita por quimioluminescência e a membrana foi exposta a filme de auto-radiografia Hyperfilm (Amersham).

Southern blot: Foi realizado de acordo com o protocolo descrito por Sambrook et al. (1989). A extração de DNA genômico foi feita conforme o protocolo de Doyle and Doyle (1987), a partir de $1 \mathrm{~g}$ de folhas de plantas de tomateiro. Após a extração, o DNA foi quantificado em $260 \mathrm{~nm}$ e $10 \mu \mathrm{g}$ foram submetidos à digestão com as enzimas Eco RV e Hind III (Promega). O produto de digestão foi submetido à eletroforese em gel de agarose $0,7 \%$ e transferido para membranas de náilon. Para a obtenção da sonda, um fragmento de $640 \mathrm{pb}$ foi amplificado por PCR a partir de $1 \mu \mathrm{L}$ de cDNAs de frutos de tomate e os oligonucleotídeos

ER49-South5'

(5'ATCTTCTCGAACTGCTGCTGAAG3') e ER49South3' (5'CCACTTCCTCAAAATACTTGCGC3'), e marcado com $\left[\alpha{ }^{32} \mathrm{P}\right] \mathrm{dCTP}$, mediante o uso do sistema Readyto-Go DNA Labelling beads (Amersham Pharmacia Biotech). Efetuou-se a hibridação em condições de baixa estringência a $42^{\circ} \mathrm{C}$, expondo-se, em seguida, as membranas a filmes de autoradiografia para a detecção do sinal.

\section{RESULTADOS E DISCUSSÃO}

Isolamento da extremidade $5^{\prime}$ e analise da seqüência protéica: O tamanho do fragmento (seqüência codificante) de cDNA de ER49 originado pelo Differential Display era de $199 \mathrm{pb}$, e a estratégia utilizada permitiu a obtenção da extremidade 5' do clone. O clone ER49 completo (NA AF096247) perfaz um total de $1,7 \mathrm{~Kb}$ e contém uma fase aberta de leitura de $1,2 \mathrm{~Kb}$, codificando um peptídio de 391 aminoácidos, cujo peso molecular predito é 42,7 KDa e o ponto isoelétrico (pI) teórico, de 8,75.

A partir dessa seqüência aminoacídica, realizou-se a pesquisa de homologias entre ER49 e outros genes já publicados, por meio do programa BLAST (Altschul et al., 1997), sendo reveladas homologias com, aproximadamente, 50 fatores de elongação da síntese de proteínas do tipo Ts (EF-Ts), confirmando os resultados obtidos para o fragmento oriundo do Differential Display e evidenciando novas homologias com EF-Ts mitocondriais de Homo sapiens e de Bos taurus.

De tais seqüências, as que apresentaram maior homologia com ER49, foram comparadas a ela pelo programa Alin (Person et al., 1997). A proteína apresentou a mais forte homologia com um potencial EF-Ts de Arabidospis thaliana (64\%), e homologias menores com EF-Ts de organismos procariotos (E. coli, Thermus thermophilus e Spirulina platensis), bem como com os EFTs mitocondriais animais (tabela 1). Como nenhum EF-Ts mitocondrial foi isolado até hoje no reino vegetal, somente a comparação com essas proteínas do reino animal foi possível, o que explicaria as baixas homologias obtidas $(24,3 \%$ com Homo sapiens e 22,6 \% com B. taurus). As homologias de ER49 com EF-Ts cloroplásticos, caracterizados unicamente em vegetais inferiores, são ainda menores que as encontradas para os organismos procariotos $(20,5 \% \mathrm{com}$ EF-Ts cloroplástico de Porphyra purpurea) ilustrando a diferente origem endossimbiótica de mitocôndrias (provenientes de proteobactérias) e de cloroplastos (oriundas de cianobactérias) (Watley et al., 1979). 
Tabela 1. Homologia entre a seqüência protéica de ER49 de tomate (Lycopersicon esculentum Mill.) e outros EF-Ts (Person et al., 1997).

\begin{tabular}{lccc}
\hline Organismo & № Acesso (GenBank) & Homologia (\%) & Classificação \\
\hline Arabidopsis thaliana (EF-Ts) & T01921 & 64,4 & eucarioto \\
Bartonella quintana (EF-Ts) & Q9XCM5 & 33,7 & proteobactéria \\
Mesorhizobium loti (EF-Ts) & NP_102414 & 31,6 & proteobactéria \\
Pseudomonas aeruginosa (EF-Ts) & $\mathrm{O} 82851$ & 28,2 & proteobactéria \\
Escherichia coli (ET-Ts) & $\mathrm{P} 02997$ & 27,7 & proteobactéria \\
Spirulina platensis $(\mathrm{EF}-\mathrm{Ts})$ & $\mathrm{P} 34828$ & 26,5 & cianobactéria \\
Homo sapiens (EF-Ts mitocondrial) & $\mathrm{NP} 005717$ & 24,3 & eucarioto \\
Streptomyces coelicolor (EF-Ts) & $\mathrm{O} 31213$ & 23,9 & actinobactériea \\
Thermus thermophilus (EF-Ts) & $\mathrm{P} 43895$ & 22,9 & deinococcus \\
Bos taurus (EF-Ts mitocondrial) & $\mathrm{P} 43896$ & 22,6 & eucarioto \\
Porphyra purpurea (EF-Ts cloroplástico) & $\mathrm{NP} 053858$ & 20,5 & eucarioto \\
\hline
\end{tabular}

A partir desses resultados, efetuou-se um alinhamento múltiplo, entre as seqüências mais homólogas e/ou correspondentes a EF-Ts, cuja função bioquímica foi demonstrada (figura 1) com o auxilio do programa Multalin (Corpet, 1988). O alinhamento múltiplo mostra a existência de várias seqüências consenso entre $E R 49$ e os diversos EF-Ts. Tais seqüências consenso estão localizadas nas regiões identificadas como domínios TS-N e EF-Ts, os quais também foram identificados nas proteínas homólogas à ER49 (figura 2). O domínio TS-N, também chamado Nterminal, está envolvido na interação com EF-Tu e é composto de 3 alfa hélices. Em ER49, está situado entre a metionina 72 e a arginina 108. O domínio EF-Ts está envolvido na associação com o complexo EF-Tu•GDP, induzindo a reciclagem deste último em GTP. Em ER49, está situado entre a alanina 123 e a glutamina 373 . Identificouse, ainda, um motivo denominado EF-TS 2, de seqüência consenso E-[LIVM]-[NV]-[SCV]-[QE]-T-D-F-V-[SA][KRN], em N-terminal.

Também se detectou a presença de um peptídio sinal de endereçamento para a mitocôndria, em N-terminal (Claros and Vincens, 1996). Este peptídio, constituído de 62 aminoácidos (mais longo que a média de 40 resíduos), tem um peso molecular predito de 6,9 KDa e um pI teórico de 10,11. Os peptídios sinal de endereçamento para a mitocôndria presentes em vegetais (Sjoling and Glasser,
1998) apresentam duas regiões distintas. Em N-terminal encontra-se o domínio de importação, que comporta estruturas carregadas positivamente expostas na superfície da proteína, o que permite guiá-la em direção à organela alvo. Em C-terminal, situa-se o domínio de clivagem, a qual é efetuada pela peptidase de processamento mitocondrial. Este sítio deve ser suficientemente conservado para ser reconhecido pela enzima. No caso da proteína ER49, o sítio de clivagem RRY*SAE é altamente conservado (Sjoling and Glasser, 1998), apresentando uma arginina em posição -3 (como em $44 \%$ dos peptídios sinal analisados), uma arginina em posição -2 (36\%), uma tirosina em posição $1(16 \%)$, uma serina em $+1(36 \%)$ e uma alanina em $+2(8$ $\%)$. Além destas, o peptídio sinal apresenta outras características importantes para o endereçamento mitocondrial (Tanudji et al., 1999), a seqüência é rica em aminoácidos carregados positivamente $(\mathrm{K}+\mathrm{R}+\mathrm{H}=19,3 \%)$ e hidroxilados $(\mathrm{S}+\mathrm{T}+\mathrm{Y}=27,4 \%)$, e empobrecida em aminoácidos carregados negativamente (D + E + 1,6\%)

A estrutura terciária de ER49, predita com o auxílio do programa SwissModel, descrito por Guex e Peitsch (1999), mostra uma conformação espacial característica dos fatores de elongação do tipo Ts (Zhang et al.,1997), indicando que a proteína teria condições de interagir com EF-Tu $\bullet$ GDP, para promover a reciclagem de GDP em GTP (figura 3). 


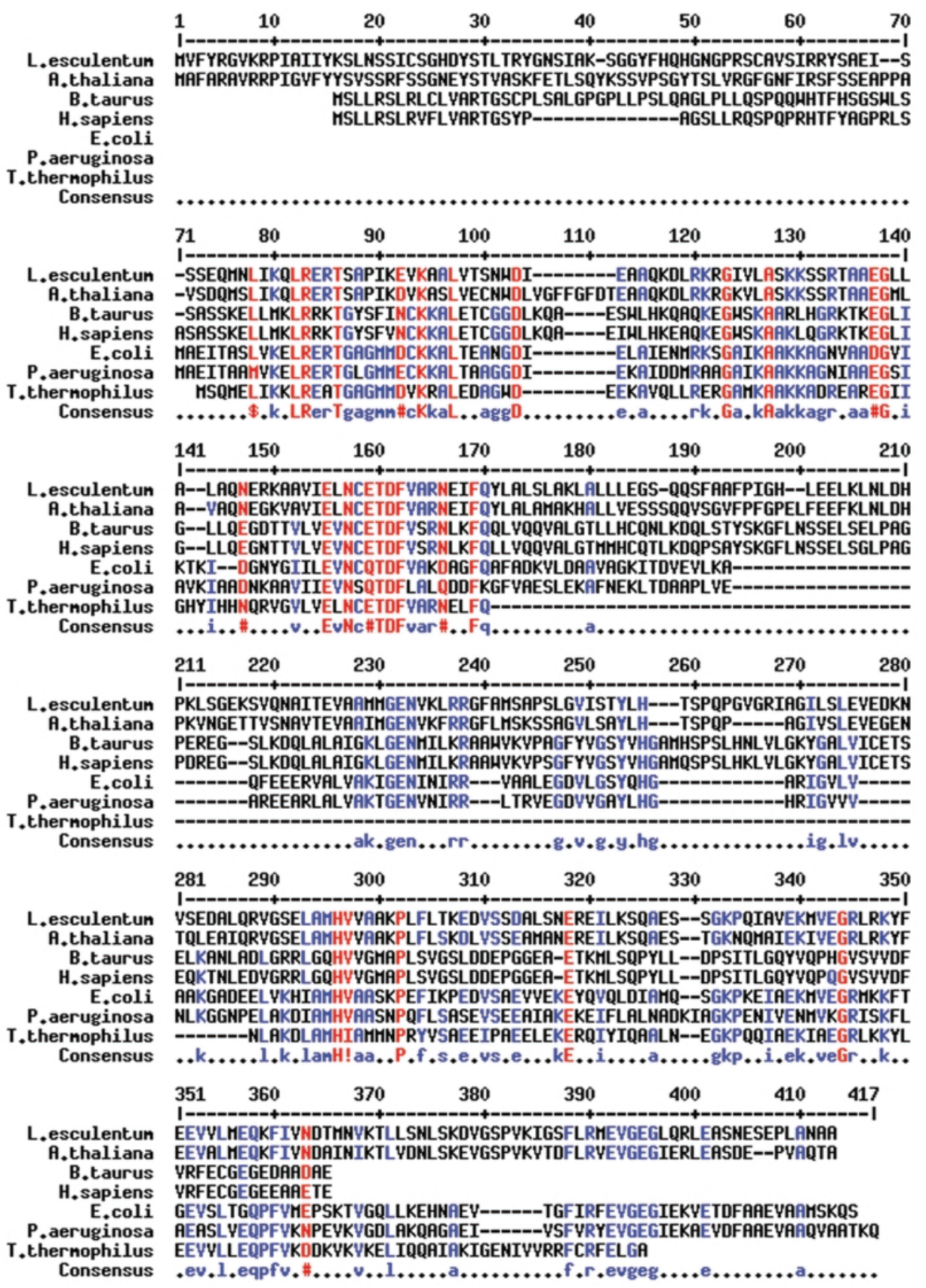

Figura 1. Alinhamento das seqüências protéicas preditas de ER49 de tomate (Lycopersicon esculentum Mill.) e de seus homólogos conhecidos (Corpet, 1988). Alto consenso (90 \%): vermelho; baixo consenso (50 \%): azul; ! = I ou V; $\$=\mathrm{L}$ ou M; \# = N, D, Q, E, B ou Z. 


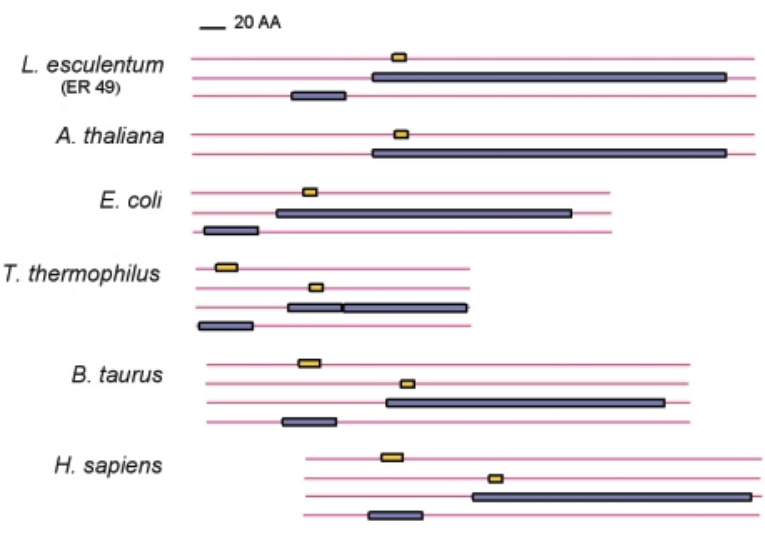

EF-TS 2
EF-TS TS-N

EF-TS 2
EF-TS

EF-TS 2 TS-TS

EF-TS 1

EF-TS 2
EF-TS
TS-N

EF-TS 1 EF-TS 1
EF-TS 2 EF-TS

EF-TS 1

EF-TS 2 EF-TS

Figura 2. Domínios TS-N e EF-Ts (em azul) e motivos EF-Ts1 e EF-Ts2 (em amarelo) identificados na seqüência de ER49 de tomate (Lycopersicon esculentum Mill.) e de seus homólogos.

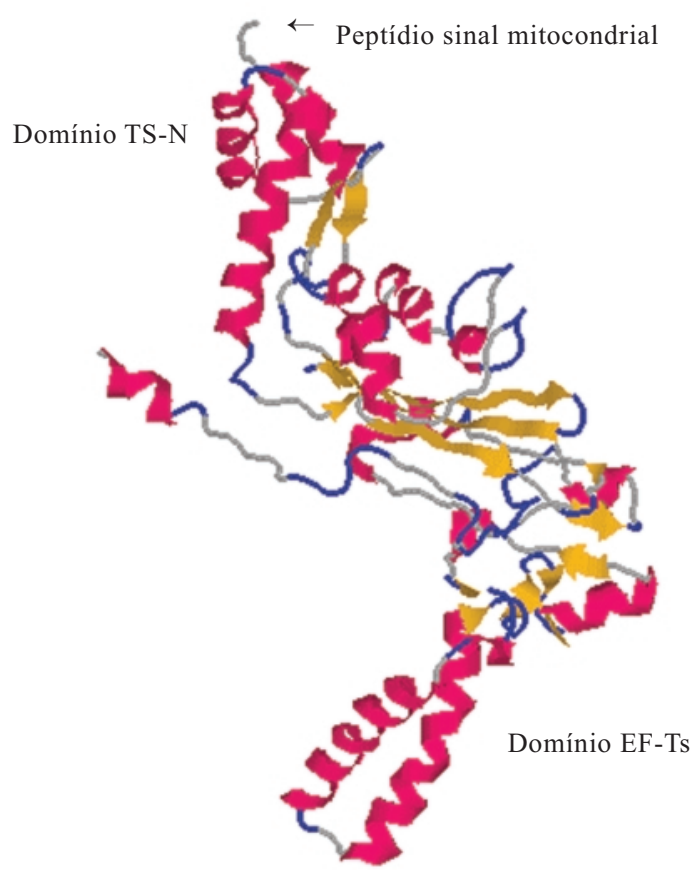

Figura 3. Representação tridimensional da estrutura de ER49 predita com o auxílio do programa SwissModel (Guex and Peitsch, 1999).
Expressão de ER49 durante a maturação de frutos de tomate var. Micro-Tom: O resultado da RT-PCR, realizada sobre RNAs que são expressos nos estádios de maturação $\mathrm{VM}, \mathrm{Br}, \mathrm{Tu}$ e $\mathrm{V}$, mostra que ER49 tem sua expressão induzida pela maturação do fruto (figura 4A), principalmente a partir do estádio Br. Esse resultado está de acordo com o encontrado por Zegzouti et al. (1999), em estudo sobre frutos da var. Evita (tomate cereja). Entretanto, na var. Micro-Tom a indução da expressão de ER49 mostrouse gradativa de um estádio a outro, com acentuada diferença de expressão entre os estádios VM e V. Para a var. Evita, no entanto, a indução ocorreu de forma abrupta a partir do estádio Tu. Esta pequena variação entre os perfis de expressão poderia ser atribuída a características inerentes às variedades de tomate, visto que os frutos da var. Evita, produzidos na maioria dos casos com fins comerciais, podem ter sofrido um processo de seleção para a obtenção de frutos com maturação ligeiramente retardada (Jimenez et al., 1996), justificando, assim, uma possível diferença na indução da expressão de genes durante o processo de maturação.

Apesar de o processo de maturação de frutos ser caracterizado por um aumento da atividade respiratória (Abeles et al., 1992), implicando, desta forma, o metabolismo mitocondrial, poucos genes mitocondriais foram descritos como regulados pelo etileno durante a maturação. Pode-se citar, entretanto, o caso do gene pKIWI505, que codifica uma subunidade $\beta$ da ATP sintase mitocondrial de quivi, segundo Ledger e Gardner (1994), o qual é induzido durante a maturação e também nos primeiros estádios de desenvolvimento do fruto, durante a divisão celular no pericarpo. De acordo esses autores, este gene é induzido nos estádios de desenvolvimento caracterizados por uma forte atividade metabólica, necessitando uma grande síntese de ATP.

Sabe-se que a crise climatérica é caracterizada por um incremento na taxa respiratória, mas não existem, todavia, dados moleculares que permitam explicar a estimulação da atividade mitocondrial durante o processo de maturação. Através de ER49, um gene nuclear com endereçamento mitocondrial, regulado pelo etileno e induzido nos últimos estádios de maturação do fruto de tomate, poder-se-ia cogitar o estudo do papel do etileno na ativação do metabolismo mitocondrial. 
Determinação do número de cópias de ER49: A determinação do número de cópias de ER49 no genoma de tomate var. Micro-Tom foi analisada por meio Southern blot. Sob as condições de baixa estringência, aparecem distintos sinais de hibridação (figura 4B). Para a digestão com Eco $\mathrm{RV}$, obtiveram-se dois sinais intensos e um terceiro sinal de hibridação de menor intensidade e, com Hind III, foram obtidos dois sinais não muito intensos. Estes são, possivelmente, devidos à presença de introns no gene. Tais resultados sugerem a presença de duas a três cópias do gene que codifica ER49 no genoma de tomate var. Micro-Tom. Como não se dispõe de informações acerca da organização gênica de homólogos, as comparações com outras espécies vegetais tornam-se difíceis.
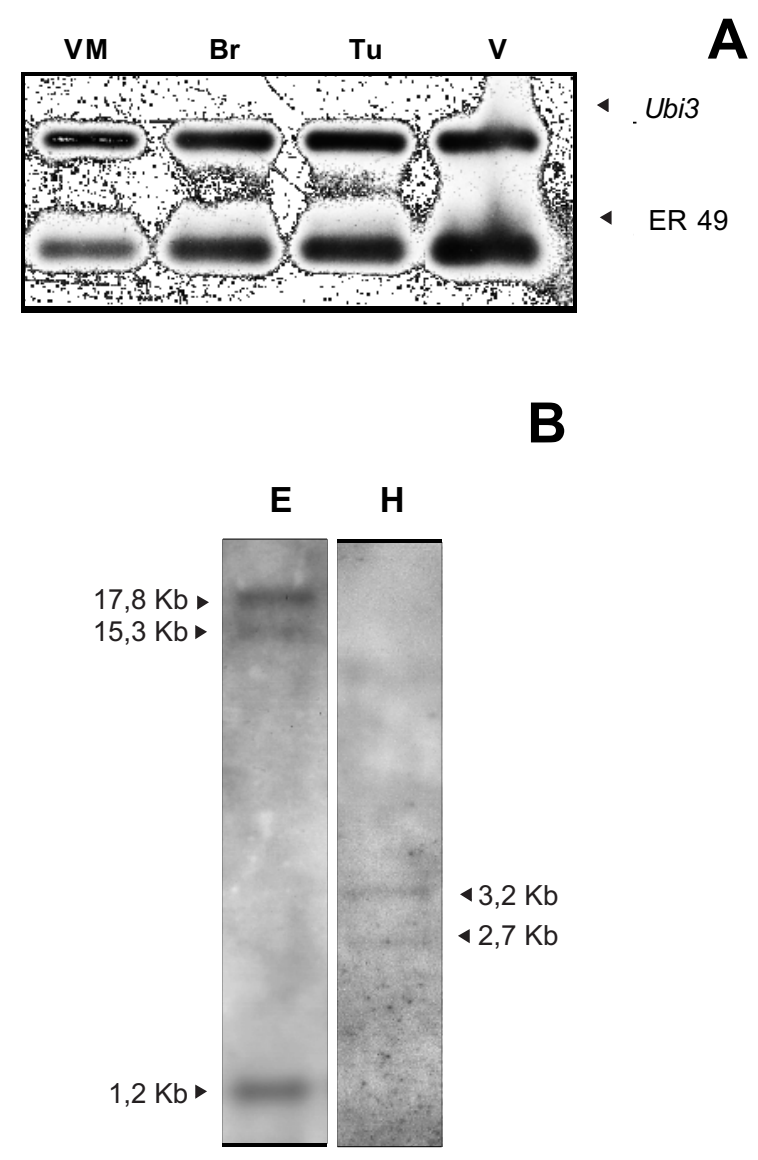

Figura 4. Expressão de $E R 49$ durante a maturação de frutos de tomate var. Micro-Tom (VM: verde-maduro; Br: breaker; Tu: turning; V: vermelho) (A) e análise do número de cópias de ER49 por Southern blot (B), utilizando-se DNA digerido com as enzimas Eco RV (E) e Hind III (H) e hibridizado com sonda marcada com $\left[\alpha_{-}{ }^{32} \mathrm{P}\right] \mathrm{dCTP}$.

\section{CONCLUSÕES}

A caracterização da seqüência peptídica e as fortes homologias verificadas com proteínas já caracterizadas, permitem classificar ER49 como um fator de elongação do tipo Ts da síntese de proteínas mitocondrial. Este gene, que parece pertencer a uma pequena família multigênica de dois a três elementos, tem sua expressão acentuada nos últimos estádios de maturação do fruto de tomate var. Micro-Tom. Entretanto, mesmo que se possa atribuir uma função bioquímica para esta proteína, as conclusões acerca de sua função no processo de maturação do fruto de tomate ainda seriam prematuras. Por esta razão, outros experimentos já estão em andamento para complementar a caracterização de ER49 ao nível bioquímico, fisiológico e celular.

\section{REFERÊNCIAS}

Abeles FB, Morgan PW, Saltveit Jr ME (1992) Ethylene in plant biology. $2^{\text {nd }}$ edn. San Diego Academic Press, San Diego.

Altschul S, Madden TL, Schaffer AA, Zhang J, Zhang Z, Miller W, Lipman DJ (1997) Gapped BLAST and PSIBLAST: a new generation of protein database search programs. Nucl. Acid Res. 25:3389-3402.

Boss, PK, Davies, C, Robinson, SP (1996) Analysis of the expression of anthocyanin pathway genes in developing Vitis vinifera L. cv. Shiraz Grape Berries and the implications for pathway regulation. Plant Physiol. 111:1059-1066.

Bouquin T, Lasserre E, Pradier J, Pech J-C, Balague C. (1997) Wound and ethylene induction of the ACC oxidase melon gene CM-ACO1 occurs via two direct and independent pathways. Plant Mol. Biol. 35:1029-1035.

Chaves, ALS (2001) Caracterização funcional do ER49, um fator de elongação mitocondrial (EF-Ts), regulado pelo etileno em tomate. Pelotas, Universidade Federal de Pelotas. Tese de Doutorado.

Chitarra MIF, Chitarra AB (1990) Pós-colheita de frutos e hortaliças: fisiologia e manuseio. Lavras, ESAL/ FAEPE, 290p.

Claros MG, Vincens P (1996) Computational method to predict mitochondrially imported proteins and their targeting sequences. Eur. J. Biochem. 241:779-786.

Corpet F (1988) Multiple sequence alignment with hierarchical clustering. Nucl. Acid Res. 16:10881-10890. 
Coupe SA, Deikman J (1997) Characterization of a DNAbinding protein that interacts with 5 ' flanking regions of two fruit-ripening genes. Plant J. 11:1207-1218.

Doyle JJ, Doyle JL (1987) A rapid DNA isolation procedure for small quantities of fresh leaf tissue. Phytochem. Bull. 19:11-15.

Filgueira FAR (1982) Manual de Olericultura. Ceres, São Paulo.

Giovannoni JJ (2001) Molecular Biology of Fruit Maturation and Ripening. Annu. Rev. Plant Physiol. Plant Mol. Biol. 52:725-749.

Gray J, Picton S, Giovannoni JJ, Grierson D (1994) The use of transgenic and naturally occurring mutants to understand and manipulate tomato fruit ripening. Plant Cell Environ. 17:557-571.

Guex N, Peitsch MC (1999) Protein modeling for all. Trends Biochem. Sci. 24:364-367.

Hamilton AJ, Lycett GW, Grierson D (1990) Antisense gene that inhibits synthesis of the hormone ethylene in transgenic plants. Nature 346:284-287.

Hoffman NE, Ko K, Milkowski D, Pichersky E (1991) Isolation and characterisation of tomato cDNA and genomic clone encoding the ubiquitin gene Ubi3. Plant Mol. Biol. 17:1189-1201.

Jimenez M, Trejo E, Cantwell M, Santellano J (1996) Cherry tomato storge and quality evaluation. Res. Summ. 13:1-10.

Lasserre E, Godard F, Bouquin T, Hernandez JA, Pech JC, Roby D, Balague C (1997) Differential activation of two ACC oxidase gene promoters from melon during plant development and in response to pathogen attack. Mol. Gen. Genet. 256:211-222.

Ledger SE, Gardner RC (1994) Cloning and characterisation of five cDNAs for genes differentially expressed during fruit developpement of kiwifruit (Actinidia deliciosa var. Deliciosa). Plant Mol. Biol. 25:877-886.

Liang P, Pardee AB (1992) Differential Display of eukaryotic messenger RNA by means of the polymerase chain reaction. Science 257:967-971.

Lincoln JE, Cordes S, Read E, Fischer RL (1987) Regulation of gene expression by ethylene during Lycopersicon esculentum (tomato) fruit development. Proc. Natl Acad. Sci. USA 84:2793-2797.
Maunders MJ, Holdsworth MJ, Slater A, Knapp JE, Bird CR, Schuch W, Grierson D (1987) Ethylene stimulates the accumulation of ripening-related mRNAs in tomatoes. Plant Cell Environ. 10:177-184.

Miller DL, Weissbach H (1977) Molecular mechanisms of protein synthesis. In: Weissbach H, Pestka S (eds), Molecular Mechanisms of Protein Synthesis. pp. 323373. Academic Press, New York.

Pech J-C, Latché A, Balagué C (1992) Cellular and molecular aspects of the plant hormone ethylene. Kluwer Academic Publishers, Netherlands.

Person WR, Wood T, Zhang Z, Miller W (1997) Comparison of DNA sequences with proteins sequences. Genomics 46:24-36.

Picton S, Gray J, Barton S, Abubakar U, Lowe A, Grierson D (1993) cDNA cloning and characterisation of novel ripening-related mRNAs with altered patterns of accumulation in the ripening inhibitor ( $\mathrm{rin}$ ) tomato ripening mutant. Plant Mol. Biol. 23:193-207.

Sambrook J, Fritsch EF, Maniatis T (1989) Molecular Cloning: a laboratory manual. Cold Spring Harbor Laboratory, New York.

Sanger F, Coulson AR (1975) A rapid method for determining sequences in DNA by primed synthesis with DNA polymerase. J. Mol. Biol. 94:441-448.

Seymour GB, Taylor JE, Tucker GA (1993) Biochemistry of Fruit Ripening. Chapman \& Hall Publishers, London.

Sjoling S, Glaser E (1998) Mitochondrial targeting peptides in plants. Trends Plant Sci. 3:136-140.

Slater A, Maunders MJ, Edwards, K (1985) Isolation and characterisation of cDNA clones for tomato polygalactorunase and other ripening related proteins. Plant Mol. Biol. 5:137-147.

Tanudji M, Sjoling S, Glaser E, Whelan J (1999) Signals required for the import and processing of the alternative oxidase into mitochondria. J. Biol. Chem. 274:1286-1293.

Watley JM, John P, Watley FR (1979) From extracellular to intracellular: the establishment of mitochondria and chloroplasts. Proc. Royal Soc. London 204:165-187. 
Zegzouti H (1997) Isolement de noveaux gènes regulés par l'éthylène chez la tomate (L. esculentum) par criblage de cDNA issus du "Differential Display". Toulouse, Institut National Polytechnique - École Nationale Supérieure Agronomique de Toulouse. $\mathrm{PhD}$ thesis.

Zegzouti H, Marty C, Jones B, Bouquin T, Latche A, Pech J-C, Bouzayen M (1997) Improved screening of cDNAs generated by mRNA Differential Display enables the selection of true positives and the isolation of weakly expressed messages. Plant Mol. Biol. Rep. 15:236-245.
Zegzouti H, Jones B, Frasse P, Marty C, Maitre B, Latché A, Pech J-C, Bouzayen M (1999) Ethylene-regulated gene expression in tomato fruit: characterization of novel ethylene-responsive and ripening-related genes isolated by differential display. Plant J. 18:589-600.

Zhang Y, Sun V, Spremulli LL (1997) Role of domains in Escherichia coli and mamalian mitochondrial elongation factor Ts in the interaction with elongation factor Tu. J. Biol. Chem. 272:21956-21963. 